\title{
ULTRASONOGRAFICAL AND CYTOLOGICAL FEATURES OF EXOPHYTIC THYROID NODULES: \\ DO EXOPHYTIC NODULES PRETEND TO BE MALIGNANT?
}

$\underline{\text { Fatma Dilek DELLAL }}^{1}$, Husniye BASER ${ }^{1}$, Didem OZDEMIR ${ }^{2}$, Aydan KILICARSLAN ${ }^{3}$, Reyhan ERSOY ${ }^{2}$, Bekir CAKIR ${ }^{2}$

\begin{abstract}
${ }^{1}$ Ataturk Education and Research Hospital, Department of Endocrinology and Metabolism, Ankara, Turkey ${ }^{2}$ Yildirim Beyazit University, Faculty of Medicine, Department of Endocrinology and Metabolism, Ankara, Turkey ${ }^{2}$ Yildirim Beyazit University, Faculty of Medicine, Department of Pathology, Ankara, Turkey
\end{abstract}

Aim

$>$ Exophytic nodule refers to a nodule that sticks out of the normal thyroid boundary/outline. Other definition is a nodule with an acute angle between the lesion and adjacent thyroid capsule. Exophytic configuration is not known risk factor for thyroid cancer. We aimed to compare ultrasonographical features and cytopathologic results of exophytic and non-exophytic thyroid nodules.

\section{Material ve Method}

$>$ Fourty-four exophytic and 34 non-exophytic thyroid nodules in which fine needle aspiration biopsy was indicated throughout 3 months were evaluated prospectively. Mean nodule size was similar in two groups $(18.83 \pm 8.71 \mathrm{~mm}$ and $15.28 \pm 7,57 \mathrm{~mm}, \mathrm{p}=0.173)$. The ratio of presence of peripheral hypoechoic halo and marginal irregularity was also similar in both group $(\mathrm{p}=0.512$ and $\mathrm{p}=0.153$, respectively). Microcalcification was present in $21.4 \%$ and $29.4 \%$ of exophytic and non-exophytic nodules, respectively $(p=0.424)$. Macrocalcification was detected in $4.5 \%$ of exophytic and $11.8 \%$ of non-exophytic nodules $(\mathrm{p}=0.111)$. $47.6 \%$ of exophytic nodules was hypoechoic and $52.4 \%$ was isoechoic. $47.1 \%$ of non-exophytic nodules was hypoechoic and 52.9\% was isoechoic. Color flow doppler pattern was defined as non-vascular, peripheral, central, or of mixed type and was similar in both groups $(\mathrm{p}=0.138)$. Cytopathologic results of exophytic nodules were $75 \%$ benign, $4.3 \%$ follicular lesion or atypia with undetermined significance, $2.3 \%$ suspicious for malignancy, $2.3 \%$ malign, and $15.9 \%$ non-diagnostic. In non-exophytic group, $79.4 \%$ was benign and $20.6 \%$ was non-diagnostic $(\mathrm{p}=0.497)$.

\section{Conclusion}

$>$ Exophytic configuration of thyroid nodules was rarely investigated as a possible predictive feature for malignancy in the literature. In the literature, only one study evaluated exophytic feature of thyroid nodules in neck CT (1). They reported malign thyroid nodules had more frequently exophytic configuration than benign ones without statistical significance. In our study, we did not find any difference in terms of ultrasonographical features and cytological results between exophytic and non-exophytic thyroid nodules. However, more comprehensive studies with larger sample sizes are needed to clarify any possible relation between exophytic configuration and malignancy.

\section{References}

$>$ Kim DW, Jung SJ, Baek HJ. Computed tomography features of benign and malignant solid thyroid nodules. Acta Radiol. 2014 Oct 7. pii: 0284185114552216. [Epub ahead of print] 